\title{
LA PENYA ROJA (COCENTAINA, ALICANTE): NUEVAS APORTACIONES PARA EL CONOCIMIENTO DEL ARTE RUPESTRE ESQUEMÁTICO Y EL TERRITORIO NEOLÍTICO EN TORNO A LA CUENCA DEL RIU PENÀGUILA
}

\author{
VIRGINIA BARCIELA GONZÁLEZ \\ Universidad de Alicante \\ FCO. JAVIER MOLINA HERNÁNDEZ
}

\begin{abstract}
El presente artículo tiene como objetivo dar a conocer un nuevo yacimiento con manifestaciones de Arte Rupestre Esquemático, Penya Roja, localizado en la vertiente este de la Serreta. Además, se ha tratado de relacionar éste y otros yacimientos de arte localizados en la cuenca del Riu Penàguila con el poblamiento durante el Neolítico de estas tierras.

Our aim in this article is to present Penya Roja, a new site with examples of Schematic Rock Art. This site is located in the eastern side of the La Serreta mountain. We have also tried to relate this site and other Schematic Rock Art sites in the Penaguila river basin with the Neolithic pattern of settlement in this area.
\end{abstract}

\section{INTRODUCCIÓN}

La zona oriental de las comarcas de l'Alcoià y el Comtat ha sido objeto de una gran tradición investigadora desde que a finales del s. XIX despertó el interés de coleccionistas y eruditos, fundamentalmente por la gran profusión de hachas de piedra pulida y otros restos arqueológicos llamativos. La importante investigación que se ha venido desarrollando desde entonces, unida a las intensas labores de prospección sistemática de los últimos años (Bernabeu et alii, 1989 y 1999; Molina, 2003), ha puesto en evidencia el intenso poblamiento que debió darse durante la Prehistoria Reciente en este territorio. Así mismo la documentación en esta zona, especialmente en la cuenca del Riu Penàguila, del principal núcleo de hábitat al aire libre de nuestras comarcas durante el Neolítico Antiguo lo convierte en un claro referente para el estudio de las primeras comunidades productoras.

Pese a la gran densidad de ocupación que se constata en sus valles y laderas los abrigos con arte rupestre son muy escasos, siendo los de El Port y El Salt de Penàguila (Beltrán, 1974; Hernández et alii 1988, 1998 y 2000), Morro Carrascal, Barranc de Frainós y Port de Confrides (Hernández et alii 1988, 1998 y 2000) los únicos conocidos hasta el momento en todo este territorio. Estos conjuntos se sitúan en el límite oriental de la cuenca del Riu Penàguila, quedando algo alejados del núcleo central de poblamiento neolítico ubicado en el curso medio y final de este mismo río y muy cerca de la falda este de la Serreta, donde no había constancia de la existencia de arte rupestre.

La sierra de la Serreta está situada en un ecosistema privilegiado, enmarcada por importantes cursos fluviales y vastas extensiones de tierras fértiles, lo que debió determinar, sin duda, su temprana ocupación y la de su entorno. Así lo demuestra la existencia en sus laderas de importantes yacimientos que pueden retrotraerse hasta el Paleolítico Medio. Destaca, al respecto, la abundante concentración de asentamientos neolíticos al mediodía de la sierra y el excepcional poblado de época ibérica que ocupa su cumbre.

Pese a ello, consideramos que en la vertiente este de la Serreta no se había llevado a cabo un estudio de campo orientado hacia la búsqueda de posibles yacimientos de Arte Rupestre. La falta de una prospección sistemática, en este sentido, pudo deberse a la escasez de abrigos o paredes con buenos lienzos que pudieran hacer suponer su existencia. A pesar de este inconveniente decidimos realizar una 


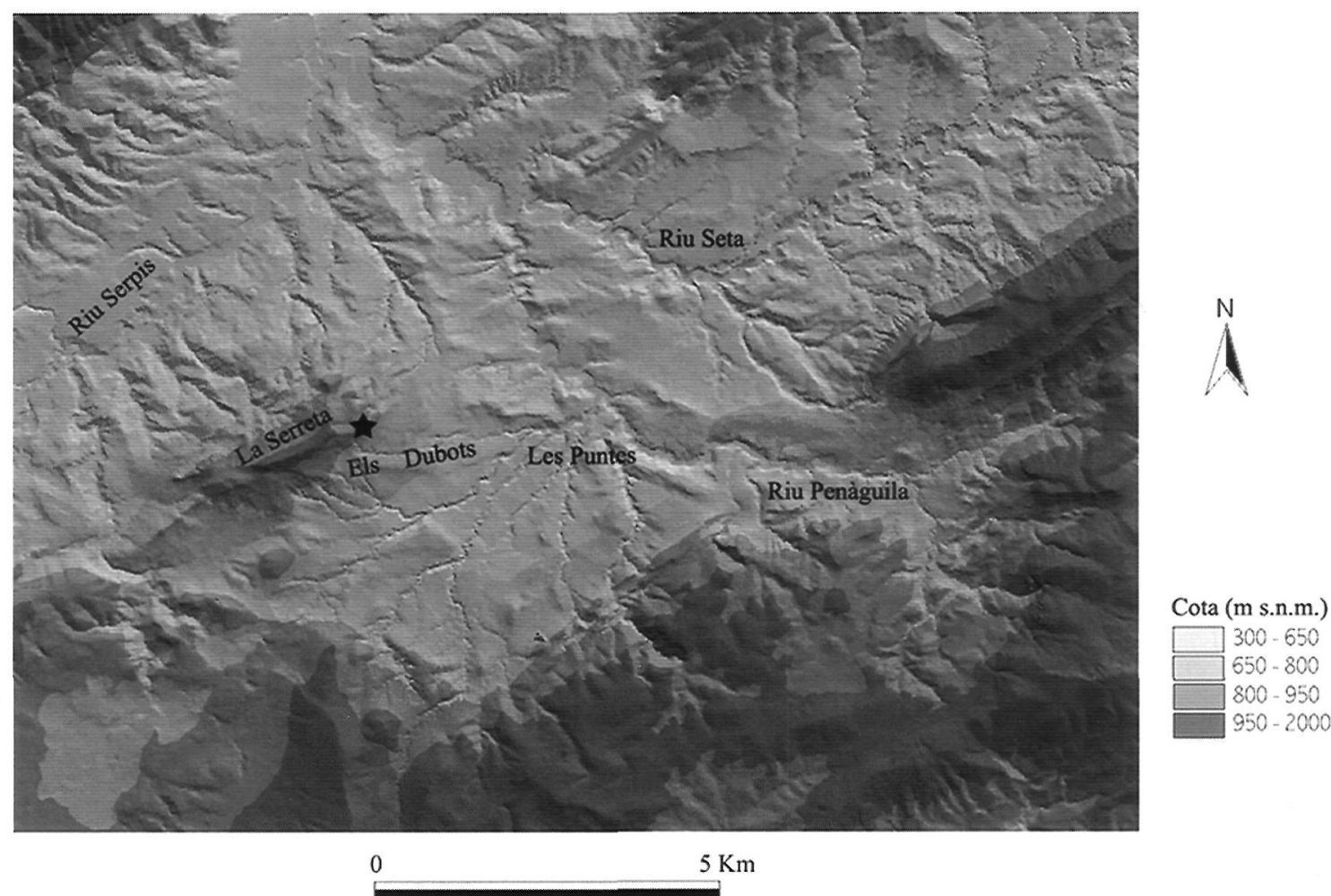

Figura 1: Ubicación de la Penya Roja en la cuenca alta del riu Serpis, comarca de El Comtat (Alicante).

intensa prospección, partiendo del interés por vincular el importante poblamiento en Ilano durante el Neolítico con las manifestaciones artísticas de tipo rupestre. El hallazgo de un nuevo conjunto de pinturas esquemáticas en la Penya Roja no sólo permite aportar nuevos datos al respecto sino que pone de relevancia la necesidad de prospectar zonas que a priori no presentan un medio geográfico con las características morfológicas o físicas idóneas.

\section{MARCO GEOGRÁFICO DE LA ZONA DE ESTUDIO}

El territorio objeto de este estudio se encuentra entre las comarcas de l'Alcoià y el Comtat, al norte de la provincia de Alicante (Fig. 1), y viene enmarcado por dos importantes hitos geográficos. El primero es el Riu Penàguila, el cual nace en las cercanías de la población de Alcoleja y se nutre de las aguas de la Serra d'Aitana y la Serrella. Su morfología se caracteriza por un trazado muy tortuoso, con numerosos meandros grandes y cerrados. Su actividad erosiva es elevada, produciendo desniveles muy acusados del orden de los $100 \mathrm{~m}$. Son muy numerosas las barranqueras que desde las zonas altas descienden hacia el valle excavadas en las endebles margas miocénicas.

La cabecera de este río está formada por el Barranc de Frainós, el Barranc del Carbó y el Riu d'Ares. A lo largo de su recorrido, en sentido sureste-noreste, atraviesa la Vall de Frainós o Penàguila y se encuentra con el Riu Seta a la altura del Mas dels Capellans (Millena). Otros cauces importantes se le unen por su margen izquierda, destacando el Barranc dels Horts, Barranc de Torresena o Barranc de l'Amagat, los cuales atraviesan las partidas de Les Puntes y Els Dubots, donde se concentra la mayor densidad de poblamiento en llano desde las primeras fases del Neolítico (Fig. 1).

El segundo hito lo constituye la sierra de la Serreta, cuya ubicación en el centro de la cuenca del Riu Sérpis le otorga una singular importancia en la geografía de las comarcas de l'Alcoià y el Comtat. Esta formación nummulítica de época terciaria (IGME, 1979) forma, junto con el Ull del Moro ( $911 \mathrm{~m}$ s.n.m.), un anticlinal alineado en sentido noreste-sudoeste, separando el valle y las laderas que se extienden hacia el este del Riu Sérpis de los valles de Penàguila, Benilloba y Benifallim, recorridos por los ríos Seta y Penàguila. Estos cursos fluviales se unen al Serpis tras sortear 


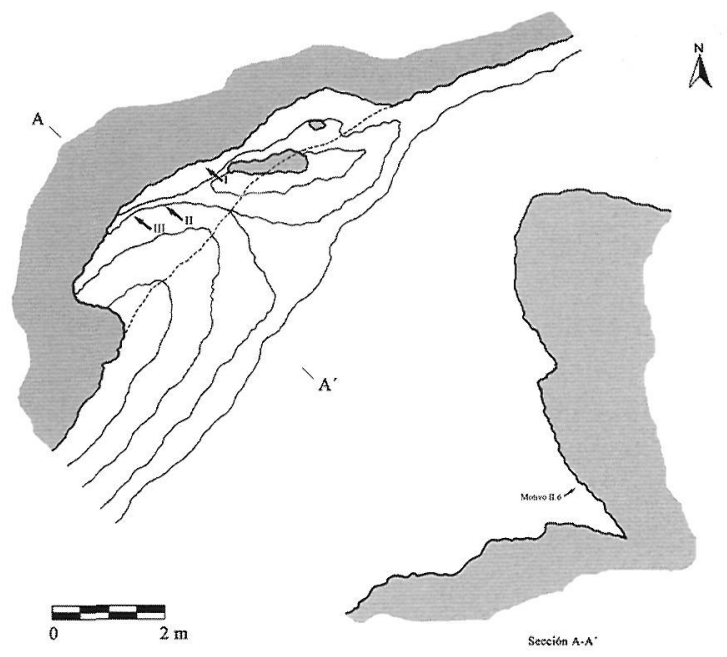

Figura 2: Planimetría de la Penya Roja.

la Serreta por su vertiente este, donde se ubica el conjunto de arte esquemático de la Penya Roja.

La zona delimitada se caracteriza, desde el punto de vista geológico, por su composición margosa de origen miocénico. Debido a la fácil erosión de estos sedimentos los cursos fluviales se encuentran fuertemente encajados en el terreno, llegando a realizar incisiones que oscilan entre los 30 y los $100 \mathrm{~m}$ de profundidad (Roselló y Bernabé, 1978), constituyendo así el paisaje abrupto y quebrado que conocemos en la actualidad.

La red de drenaje se dispone de manera centrípeta, uniéndose los barrancos entre sí o a los colectores principales. Entre ellos subsisten las zonas llanas, localmente conocidas como "puntes", donde se documenta un poblamiento neolítico singular debido a la gran densidad de yacimientos existentes. Los estudios geomorfológicos desarrollados en la zona indican que la edad de encajamiento de la red hidrográfica es reciente, ofreciendo, por tanto, una superficie bastante estable desde al menos el final del Pleistoceno (La Roca, 1991). La última gran transformación ha sido la erosión de tipo vertical realizada por los cauces actuales (Bernabeu et alii, 1999, 33) y las labores de roturación.

\section{LAS PINTURAS ESQUEMÁTICAS DE LA PENYA ROJA}

La Penya Roja se localiza en la base de una pequeña cresta caliza, a unos 800 m s.n.m, en la vertiente este de la Serreta. Se trata de una pared rocosa de unos $11 \mathrm{~m}$ de longitud que se encuentra orientada a 115 grados este. En general, la coloración del soporte rocoso es de tono anaranjado y se encuentra afectado por coladas de carbonato cálcico en su mitad inferior. Los desconchados, aunque son escasos y poco extensos, se localizan fundamentalmente en la parte media y alta del lienzo (Fig. 2).

En la base se abre una grieta, de 2,5 $\mathrm{m}$ y $0,75 \mathrm{~m}$ de profundidad y altura máximas, que resulta casi inaccesible debido a su estrechez. En uno de los extremos de la grieta hemos localizado algunos restos óseos humanos en superficie, aunque ningún elemento que nos permita adscribirlos a un período cronológico concreto. Se trata de dos dientes completos -un incisivo y un canino-, otro diente fragmentado, un fragmento de clavícula de un individuo infantil y dos fragmentos de hueso indeterminados.

El acceso al yacimiento se realiza desde la carretera que une la CV-785 (Alcoi-Benifallim) con la CV-790 (Alcoi-Benilloba). Tras pasar el Mas Gran de Pellicer y el Barranc de I'Amagat se asciende por una pista que se dirige hacia la Masía de Cosme. Desde aquí se divisa la cresta y la pared rocosa donde se localizan las pinturas. Las coordenadas U.T.M. son 30SYH244861 (Hoja de Alcoi (821-III), E: $1 / 25.000)$.

La visibilidad desde lo alto de la cresta es escasa hacia el oeste y el norte, ya que al ser el paisaje cercano eminentemente montañoso no se tiene control visual sobre el valle. La densa vegetación también dificulta en gran medida la visibilidad pero es posible observar algunas sierras lejanas como la de Almudaina $y$, parcialmente, las del Benicadell y Montcabré. Hacia el este se alcanzan a ver las sierras de Alfaro, Serrella, Aitana y el Castell de Penàguila $y$, hacia el sur, la Sierra de Penàguila, Els Plans, El Rontonar y El Puig, además de tener un perfecto dominio visual sobre el valle.

Por otro lado, desde la pared donde se localizan las pinturas la visibilidad se reduce ligeramente, siendo visibles las sierras de Almudaina, Alfaro, la Serreta de Tollos, la Serrella, la Sierra de Aitana, Penàguila, El Rontonar y Els Plans, así como las zonas llanas que quedan al sur y al este.

Además, desde la Penya Roja se domina la partida del Pla de Els Dubots, donde se ubican yacimientos neolíticos como Mas d'ls, Pla de Mitjà, Mas de Cantò o Barranc de I'Amagat; y la partida de Les Puntes, donde se ubican otros yacimientos de este mismo perío- 

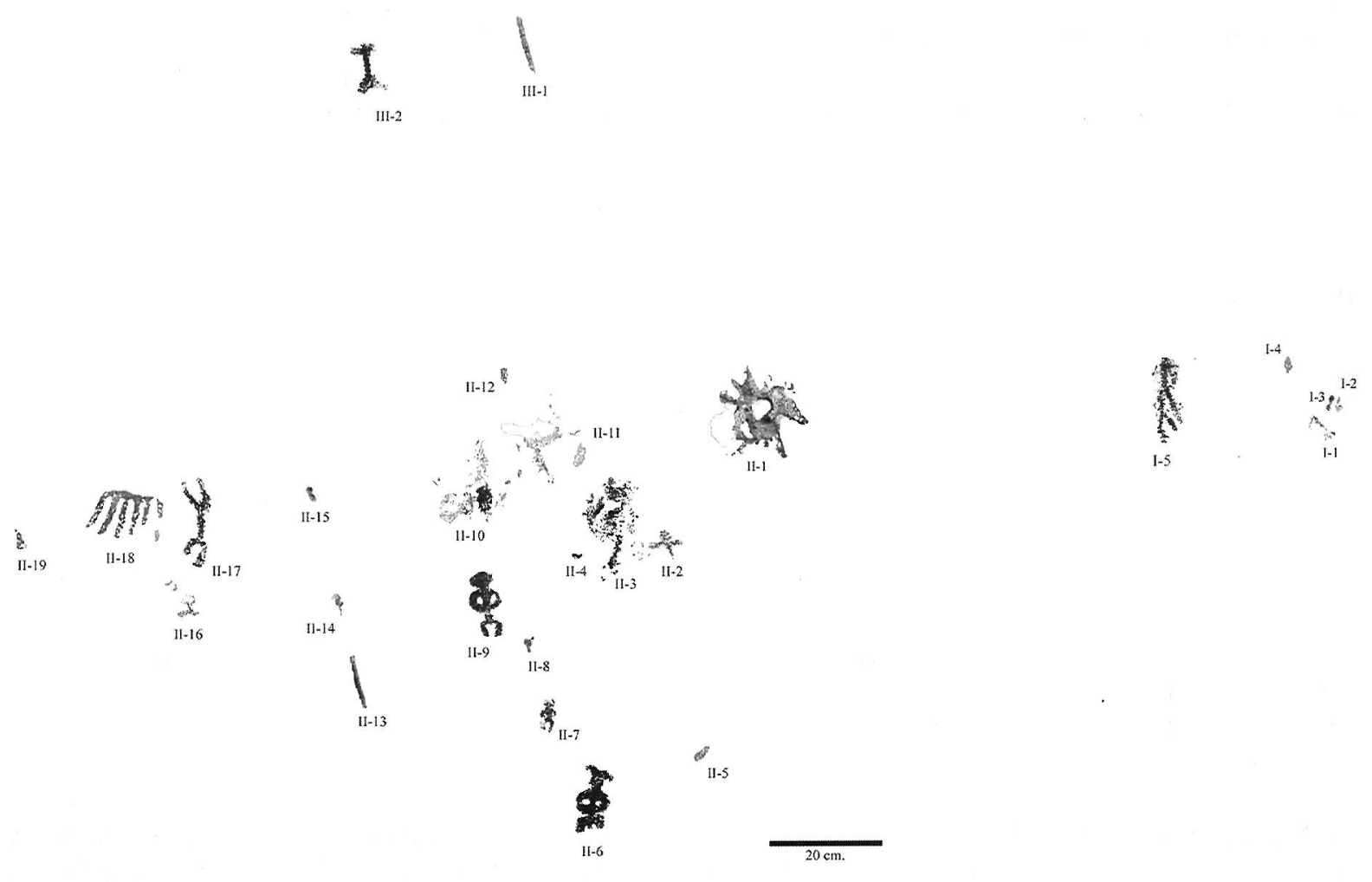

Figura 3: Paneles I, II y III.
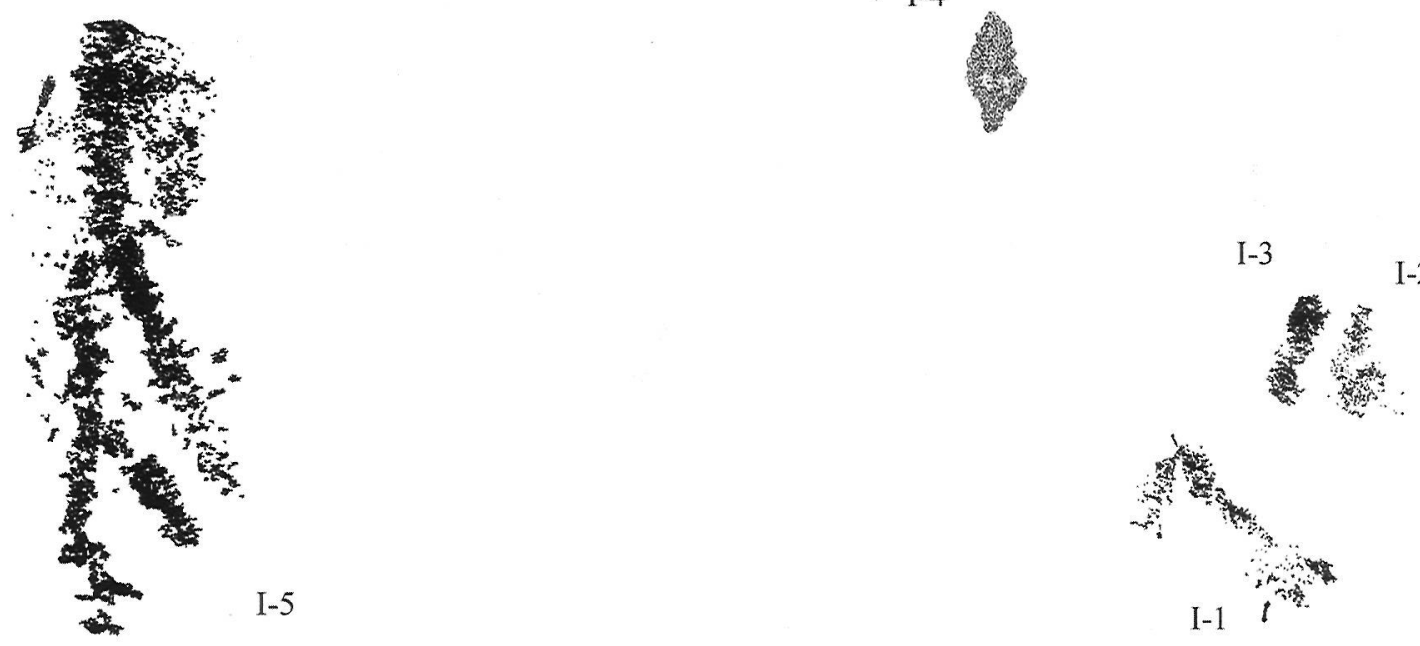

$4 \mathrm{~cm}$.

Figura 4: Panel I. 
do como Bancals de Satorre o Les Puntes (Bernabeu et alii, 1989). También se divisan algunas zonas con arte rupestre ubicadas en el extremo contrario del valle, como los situados en el Barranc de Frainós y los del Port y el Salt de Penàguila.

\section{III.1. Descripción de las pinturas}

Dentro del conjunto de Arte Esquemático hemos diferenciado tres paneles, en función de la distribución y agrupación de los motivos (Fig. 3).

Panel I (Fig. 4): Lienzo de color anaranjado claro, sin concreciones calcáreas ni desconchados que afecten a los motivos. La pintura es diluida y penetra en los huecos del soporte. La altura respecto al suelo es de 1,70 $\mathrm{m}$ (motivo 1.5).

Motivo I.1: Ángulo abierto hacia abajo. Color: M.10R 5/8

Motivo I.2: Barra oblicua. Color: M.10R 5/8.

Motivo I.3: Barra oblicua. Color: M.10R 4/4.

Motivo I.4: Mancha de contorno irregular de 4 $\mathrm{cm}$ de largo. Color: M.10R 5/8.

Motivo 1.5: Barra vertical que presenta un engrosamiento en la parte superior y una ligera inflexión en su zona media. De la parte superior, a ambos lados, parten dos trazos curvos. De la parte inferior, a la izquierda, parte otro trazo curvo y, a la derecha, dos trazos oblicuos y paralelos entre los cuales se observan otros restos de pintura. Color: M.10R 4/4.

Panel II (Fig. 5): Lienzo de color variable, con tonos blanquecinos, grisáceos y amarillentos. Muy afectado por coladas blancas de carbonatos que cubren algunos motivos. Los desconchados son abundantes, sobre todo en la parte superior de este panel, afectando parcialmente a algunas figuras. La pintura es diluida y ligeramente densa en algunos motivos, penetrando en los huecos del soporte. La altura máxima con respecto al suelo es de $1,80 \mathrm{~m}$ (motivo II.11) y la mínima es de $0,73 \mathrm{~m}$ (motivo II.16).

Motivo II.1: Soliforme formado por una mancha de tendencia circular, alrededor de una ligera depresión del lienzo, de la que arrancan 8 rayos perpendiculares. Motivo afectado por varios desconchados. Color: M.10R 4/8.

Motivo II.2: Motivo cruciforme. Color: M.10R 3/6. Motivo II.3: Motivo antropomorfo del que se conserva la cabeza de tendencia circular, un tronco ancho y las extremidades superior e inferior izquierda. La extremidad superior se alza desde el tronco y está formada por una barra curva bifurcada en su extremo. La parte derecha de la figura se encuentra afectada por una colada, aunque se aprecian restos de pintura. Color: M.10R 4/8.

Motivo II.4: Barra horizontal, ligeramente curva, de $2 \mathrm{~cm}$ de longitud. Color: M.10R4/8.

Motivo II.5: Barra vertical, ligeramente inclinada hacia la derecha, de $5 \mathrm{~cm}$ de longitud. Color: M.10R 6/8.

Motivo II.6: Figura antropomorfa, de $12,5 \mathrm{~cm}$ de longitud, formada por una barra vertical que constituye el cuerpo y el falo, brazos curvos que se unen en el tronco y piernas arqueadas cortadas por un desconchado. La cabeza está bien diferenciada, es de forma circular y está rematada por una pequeña barra horizontal ligeramente rehundida en su parte central. El motivo se encuentra afectado por una fina película de carbonato cálcico de color blanco. Color: M.10R 4/6.

Motivo II.7: Motivo antropomorfo del que se conserva parte de la cabeza circular, el tronco, la extremidad superior izquierda y el arranque de la derecha. El brazo conservado está arqueado y se une al tronco a la altura de la cintura. Las extremidades inferiores no se conservan, aunque se observan restos de pintura. Color: M.10R 5/6.

Motivo II.8: Mancha de bordes irregulares de 3 $\mathrm{cm}$ de largo. Color: M.10R 4/6.

Motivo II.9: Figura antropomorfa, de $11,5 \mathrm{~cm}$ de largo, formada por un trazo vertical que constituye el tronco, brazos curvos que se unen a la altura de la cintura y piernas arqueadas. La cabeza está bien diferenciada y presenta una forma ovalada. El motivo se encuentra afectado por una fina película de carbonato cálcico. Color: M.10R 4/6.

Motivo II.10: Restos de pintura entre los que se pueden identificar un barra vertical unida a otro motivo circular. Color: M.10R 4/8 y 5/8.

Motivo II.11: Motivo circular abierto afectado por desconchados. Color: M.10R 4/8.

Motivo II.12: Barra vertical de $3 \mathrm{~cm}$ de longitud. Color: Color: M.10R 4/8.

Motivo II.13: Barra vertical, de $10 \mathrm{~cm}$ de longitud, ligeramente inclinada a la izquierda. Color: M.10R 3/6.

Motivo II.14: Barra vertical, de $4 \mathrm{~cm}$ de longitud, ligeramente inclinada a la izquierda. Color: M.10R 4/8.

Motivo II.15: Barra vertical, de $3 \mathrm{~cm}$. de longitud, ligeramente inclinada a la izquierda. Color: M.10R 4/8. 


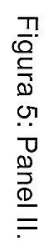
홍

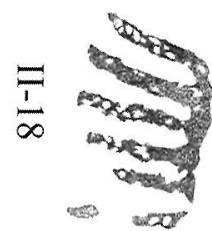

言

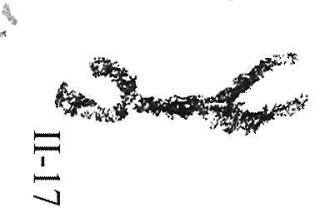

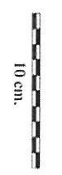

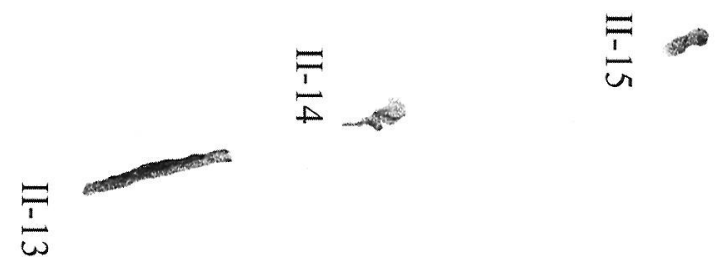

à

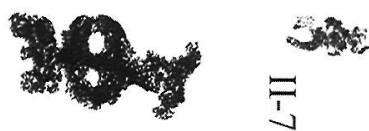

Fi
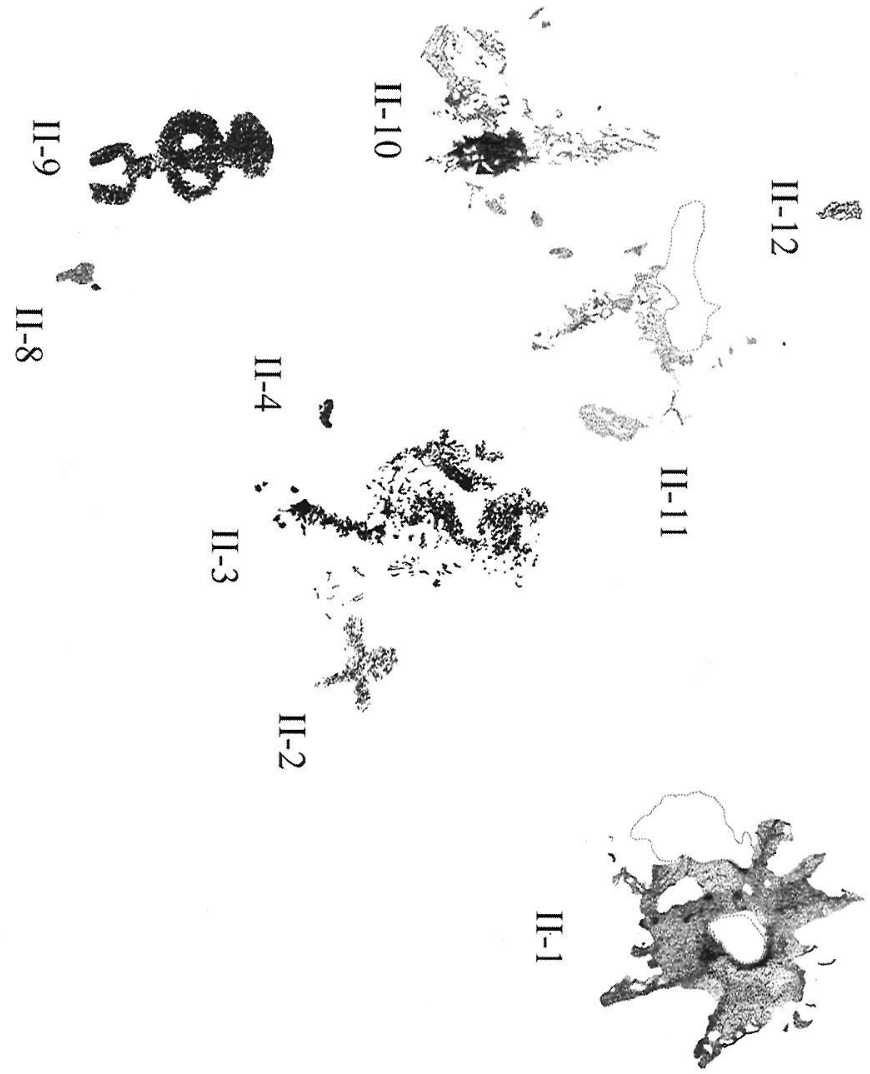


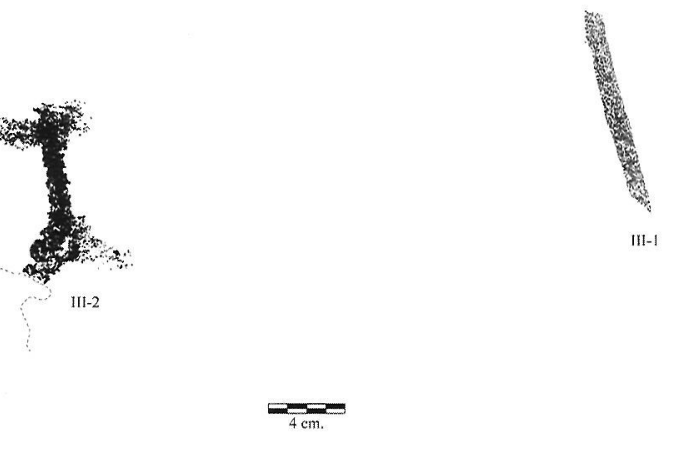

Figura 6: Panel III.

Motivo II.16: Restos de pintura entre los que se pueden identificar dos manchas de tendencia circular y una alargada en la parte superior. Color: M.10R 5/6.

Motivo II.17: Antropomorfo en doble $Y$ de 16,2 $\mathrm{cm}$ de largo. La figura presenta las extremidades superiores e inferiores ligeramente inclinadas hacia la izquierda. Otros restos de pintura hacen pensar que pudo tener la cabeza indicada. El motivo está cubierto casi en su totalidad por una fina película de carbonato cálcico. Color: M.10R 3/6.

Motivo II.18: Pectiniforme horizontal formado por dos trazos curvos contiguos, en la parte superior, de los cuales arrancan seis barras perpendiculares, cuatro del izquierdo y dos del derecho. El motivo está parcialmente afectado por la descalcificación del lienzo, especialmente su parte derecha. Color: M.10R 4/4 y M.10R 5/6 en las zonas afectadas por la colada.

Motivo II.19: Mancha de $4 \mathrm{~cm}$ de largo por 2 $\mathrm{cm}$ de anchura máxima. Color: M. 10R 6/8.

Panel III (Fig. 6): Lienzo anaranjado-rojizo bastante bien conservado. Presenta algunos desconchados y concreciones calcáreas que no afectan a las pinturas. Se encuentra ubicado en la parte más alta en relación a los otros paneles. La altura respecto al suelo del motivo I. 1 es de $2,33 \mathrm{~m}$. La pintura es ligeramente densa y penetra en los huecos del soporte.

Motivo III.1: Barra vertical de $10 \mathrm{~cm}$ de largo y $1,5 \mathrm{~cm}$ de ancho. Color: M.10R 4/8.

Motivo III.2: Antropomorfo de 9,7 cm de largo formado por una barra vertical que constituye el cuerpo y la cabeza, brazos ligeramente alzados y piernas abiertas en forma de "V" invertida. Color: M.10R 4/8.

Junto a las pinturas también hemos identificado algunos grabados más modernos que daremos a conocer en un posterior trabajo.

\section{III.2. Análisis tipológico}

La Penya Roja cuenta con un total de 26 motivos, distribuidos en tres paneles distintos. Entre ellos se han podido identificar figuras antropomorfas, pectiniformes, soliformes, ángulos, barras y manchas informes.

Los motivos más abundantes en el yacimiento son los antropomorfos, contabilizándose un total de 9 de estas figuras. Los tipos establecidos son los antropomorfos de tipo "phi", los de tipo cruciforme, los que presentan una morfología en doble "Y" y un último antropomorfo con un brazo alzado y bifurcado difícilmente encuadrable en alguno de los tipos establecidos para el Arte Esquemático.

El más representado es el antropomorfo de tipo "phi". En el Panel I, hemos interpretado la figura 1.5 como dos antropomorfos de este tipo en base a un detallado análisis de la pintura en las zonas peor conservadas. Un antropomorfo de mayor tamaño, situado en la parte superior, del que se conserva la cabeza -engrosamiento superior-, el tronco, las extremidades superiores -dos trazos curvos a ambos lados-, la extremidad inferior izquierda -constituida por una barra oblicua- y el arranque de la extremidad inferior derecha -constituida por una parte de la barra vertical-. Esta barra vertical presenta una inflexión en su parte intermedia de la que podría arrancar otro antropomorfo más pequeño formado por una larga barra, que constituye la cabeza, el tronco y la extremidad inferior derecha, de la que, a su vez, parte la extremidad inferior izquierda. Las extremidades superiores no se conservan bien, aunque se observan restos de pintura que podrían hacer pensar, con muchas reservas, en dos brazos curvos unidos a la altura de la cintura, como en el caso del motivo superior. Cabe destacar que esta figura también recuerda a los motivos ramiformes, entendidos por algunos autores como un motivo antropomorfo (Hernández et alii, 2000, 38).

Más claras resultan las figuras II.6, II.7 y II.9. Las tres presentan cabezas de morfología circular u oval, los brazos en asa y las piernas arqueadas. Especial mención merece la figura II.6 en la que el falo está indicado y en cuya cabeza aparece una barra horizontal que podría representar un peinado o algún tipo de adorno para el que no hemos encontrado paralelos en los yacimientos de arte rupestre de nuestras comarcas.

Otro tipo de antropomorfo es el cruciforme. Tan sólo encontramos un motivo de 
este tipo (II.2) en el yacimiento, formado por dos trazos cruzados perpendicularmente y la cabeza claramente indicada. Si bien los brazos no están curvados hacia abajo la figura recuerda también a los antropomorfos de tipo golondrina, en los que no se representan las extremidades inferiores. Incluso se aproxima, tipológicamente, a los motivos con forma de " $X$ ", ya que la figura se encuentra ligeramente inclinada.

El motivo en doble $Y(I I .17)$, representado en el Panel II, también se ha interpretado como un antropomorfo. Es posible que presentara la cabeza señalada, a juzgar por algunos restos de pintura. La inclinación de las extremidades y la representación de una de las piernas más corta le confieren una cierta sensación de movimiento. También la figura III.2 se encuentra tipológicamente muy próxima a la doble $Y$, al estar representada con los brazos ligeramente alzados y las piernas abiertas en $\checkmark$ invertida. En este motivo sí se observa claramente la cabeza indicada, pero las extremidades son más cortas.

El antropomorfo II.3 presenta, también, uno de los brazos alzados, lo que permitiria aproximarlo a los anteriores motivos. Sin embargo, la singularidad de ese brazo bifurcado y la factura recuerdan a los convencionalismos empleados en algunas representaciones macroesquemáticas (Pla de Petracos. Abrigo IV, panel I). Cabe destacar, también en este sentido, que la figura presenta una cabeza grande de morfología circular y un tronco considerablemente más ancho que los del resto de motivos del conjunto.

Otro tipo de motivos representados en la Penya Roja son los pectiniformes, los cuales se podrían interpretar como zoomorfos esquematizados. En este caso sólo se documenta uno (motivo II.18), formado por una barra horizontal curva de la que parten seis barras perpendiculares.

Los motivos soliformes, tan característicos del Arte Esquemático, también están presentes en la Penya Roja. La figura II.1 no deja lugar a dudas, aunque es probable que los motivos circulares indeterminados (II.11 y II.10) también correspondan a este tipo.

Por último, encontramos algunos motivos geométricos, como los ángulos y las barras. Respecto a las barras, su interpretación es difícil, debido a la elevada esquematización, aunque se ha apuntado a una posible relación con la figura humana (Martí y Hernández, 1988, 48; Hernández et alii, 2000, 36). Cabe destacar las dos barras paralelas y ligeramente inclinadas del Panel I (I.2 y I.3) y las tres barras (II.13, II.14 y II.15) que aparecen alineadas en el Panel II. En los yacimientos esquemáticos de Alicante no se han documentado este tipo de barras partidas y alineadas, a excepción de la serie de barras verticales del panel 2 de l'Arc de Santa Llúcia en el Salt de Penàguila. Lo habitual, en otros yacimientos como la Cova dels Llidoners o en el Abric de Sant Antoni (Molina y Segura, 2001), es la aparición de conjuntos de barras verticales y paralelas pero continuas.

Por otro lado, el único ángulo que aparece representado (I.1) está abierto hacia abajo. Este tipo de figuras son, igualmente, de difícil interpretación. Aunque aquí el motivo aparece aislado, en algunos yacimientos como la Penya Escrita de Tàrbena encontramos una extraordinaria concentración de ellos (Hernández et alii, 2000, 281).

En general, todos los motivos tienen paralelos no sólo en esta zona sino en otros puntos de la provincia de Alicante. En el yacimiento cercano del Salt de Penàguila encontramos motivos en doble $\mathrm{Y}$, pectiniformes, barras, ángulos y algunas figuras que presentan las piernas curvas y el falo indicado o los brazos en asa, sin que éstos lleguen a confluir en la cintura. En el resto de conjuntos cercanos también encontramos algunas figuras similares a las de Penya Roja, como algunas barras y un motivo en $\mathrm{Y}$, en Morro Carrascal; un pectiniforme de seis barras y un soliforme cuyos rayos parten de un rehundimiento natural, en el Port de Penàguila y otras barras en el Port de Confrides y el Barranc de Frainós. Sólo hay dos figuras que plantean algunos problemas al respecto. La primera es la figura II.3 que, aunque presenta los brazos levantados como otros motivos esquemáticos, muestra ciertos convencionalismos que se alejan de lo que es este tipo de arte. La segunda es la figura II.6, en la que destaca un tipo de adorno o peinado para el que no hemos encontrado paralelos en esta zona. Sólo en algunos conjuntos del sur peninsular aparecen figuras que presentan en la cabeza elementos similares, como es el caso de un antropomorfo de la "Cueva de la Vereda de la Cruz" en Sierra Arana, Granada (Soria y López, 1988-1989, 177). Del mismo modo, también cabe destacar que en ninguno de los yacimientos próximos encontramos figuras antropomorfas de tipo "phi" como las existentes en la Penya Roja. El yacimiento más cercano con un motivo antropomorfo claramente perte- 
neciente a este tipo es La Sarga (Alcoy). También sorprende el elevado número de estos motivos en el yacimiento, teniendo en cuenta que no son frecuentes en los conjuntos de Arte Esquemático de las comarcas alicantinas.

\section{III.3. Estudio de la composición y del em- pleo del soporte}

Respecto a la composición es importante destacar algunas características que proporcionan información acerca de la ejecución de las pinturas y de su significado.

De forma general podemos decir que se trata de un conjunto bastante homogéneo, en cuanto a la factura de las figuras y su distribución ordenada en el lienzo y sin superposiciones. No obstante, no por ello podemos afirmar con total seguridad que se trate de un conjunto efectuado en un solo momento.

Quizás el análisis del panel y de cómo se ordenan los diversos elementos en el mismo también puedan contribuir al conocimiento del significado de este Arte, tal y como apuntan algunos trabajos recientes (Martínez, 2002). En esta línea, la propia división de los paneles se ha realizado en base a la distribución intencional, por parte de los ejecutores, de los motivos en el espacio. Los tres paneles aparecen separados bien por grietas con cierta entidad y cambios en la morfología del soporte, como es el caso del panel II y el panel III; o bien por grandes espacios en los que no hay pinturas, como es el caso del panel I y el panel II. Sólo en el panel II encontramos un motivo pintado que podría constituir un elemento de separación entre unas composiciones y otras.

Los paneles I y III de la Penya Roja no presentan suficientes motivos como para analizar en profundidad su distribución. Lo único destacable es la asociación de dos barras oblicuas en el panel I y la horizontalidad de los motivos en ambos paneles, lo que, quizás, podría permitir vincular unas figuras con otras.

Sin embargo, en el panel II si que se observan tres grupos de motivos bien diferenciados que podrían constituir composiciones distintas. Además, la barra discontinua (II.13, II.14 y II.15) localizada entre dos de los conjuntos podría haber sido realizada, precisamente, para separarlos. El primero de estos grupos es el compuesto por el pectiniforme (motivo II.18) y la doble $Y$ (II.17). Su proximidad física y técnica, la horizontalidad de los motivos y la sensación de dinamismo que se desprende de la representación del antropomorfo parece señalar que se trata de una composición, eso sí, de difícil interpretación. Además, esta asociación es recurrente dentro del Arte Esquemático, ya que se documenta en otros yacimientos como el cercano Salt de Penáguila (Abrigo VI, Panel 1) y, en el sur peninsular, el Abrigo de Julio Martínez (Sierra Arana, Granada) (Soria y López, 1988-1989).

En el segundo de los conjuntos se observa una figura central antropomorfa (II.3), de mayor tamaño que el resto de motivos de este tipo y con características tipológicas singulares. A su lado encontramos otro antropomorfo y, en la parte superior, un soliforme y otros dos grandes motivos circulares casi alineados. La asociación de motivos soliformes la encontramos en algunos abrigos esquemáticos como en el Barranc de la Cova Jeroni (Vall de Gallinera) o la Penya de l'Ermita del Vicari (Altea), lo que podría reforzar la idea de que estos motivos circulares son soliformes deteriorados. Nos encontramos, por tanto, ante una composición en la que distinguimos tres categorías de motivos. Los que se encuentran en la parte superior, la figura central y. una figura satélite que acompaña a este motivo principal.

Por último, el tercer conjunto, separado del anterior por una inflexión en el lienzo y por cierta distancia de los motivos anteriores, se compone únicamente de tres figuras antropomorfas de tipo "phi". Una más grande en la parte superior, con la cabeza ovalada como único elemento resaltado; otra en la parte intermedia, de menor tamaño y sin características especiales; $y$ otra figura masculina presenta el falo indicado- en la parte inferior, de igual tamaño que la primera y con un peinado o adorno en la cabeza que la convierten en la figura más destacada. Nos encontraríamos, por tanto, ante una composición de tres figuras alineadas verticalmente, aunque en sentido diagonal, en la que las dos figuras de los extremos son grandes y presentan cabezas con morfología singular y la figura intermedia es más pequeña y sin elementos destacados.

Por otro lado, es probable que el soporte rocoso haya sido empleado para recalcar algunas figuras dentro del conjunto o para dar relieve y sensación de movimiento. En el caso de la figura antropomorfa II.3, se ha seleccionado la zona central de la pared para ejecutarla. Esto, unido a las características singulares que presenta, contribuye a dar un papel relevante a la figura. Igualmente relevantes pare- 
cen ser los motivos III.1 y III.2. Éstos se localizan en la parte superior del lienzo y en una zona bien visible, aunque sus características técnicas o tipológicas no son excepcionales, como en èl caso anterior.

La ejecución del soliforme ll.1 en torno a un rehundimiento del lienzo, tampoco parece casual, ya que contribuye a dar volumen al motivo. Además, está situado en la parte alta del Panel II, por encima del resto de figuras, lo que supone una plasmación realista. El empleo de un rehundimiento en el soporte se constata, también, en un soliforme representado en el conjunto cercano del Port de Penàguila.

Por último, otra figura a destacar es el antropomorfo en doble "Y". Éste se ha efectuado en una zona de inflexión de la pared rocosa, dando la impresión de que la figura está "colgada" del lienzo e incrementando la sensación de dinamismo.

\section{III.4. Análisis de la técnica y el color}

En recientes trabajos sobre arte rupestre (Torregrosa, Galiana y Ribera, 2001) el análisis de la técnica y el color en la elaboración de los motivos se ha llevado a cabo no sólo como una categoría más dentro del estudio concreto del conjunto sino, también, como un elemento de contextualización, contribuyendo a la caracterización del Arte Esquemático en determinados territorios. En esta línea hemos tratado de profundizar en algunos aspectos, siempre que la conservación de los motivos lo ha permitido.

Respecto a la técnica empleada observamos que todas las figuras están realizadas en tinta plana, con un único trazo de contorno irregular que constituye la totalidad de la figura y que, pocas veces, supera los $1^{\prime} 5 \mathrm{~cm}$ de anchura.

Para la determinación del color empleado en el yacimiento hemos utilizado la tabla Munsell Soil Color Charts. El color de los motivos de este conjunto es exclusivamente el rojo, si bien hemos documentado diferentes tipos de intensidad y algunas variaciones en cuanto a la tonalidad. También se han registrado diferenciaciones en cuanto a la densidad del pigmento utilizado.

Panel I. En este panel encontramos dos colores, un rojo débil (M10R 5/8), en los motivos I. 1, I.2 y 1.4 y un rojo (M10R $4 / 4$ ) en el resto de motivos. La pintura es diluida en ambos casos y penetra en el soporte, aunque los motivos pintados en rojo presentan un pigmento ligeramente más denso. Si bien se observa que las figuras en rojo débil se localizan a la derecha del panel, cabe destacar que los motivos I.2 y 1.3, que forman dos barras paralelas, presentan intensidades de rojo distintas.

Panel II. En el panel II encontramos una mayor variedad cromática, aunque la mayoría de los motivos presentan un color rojo (M10R $5 / 8$ ) y una pintura bastante diluida. Estas figuras se concentran en la parte derecha y central del panel. No obstante, la figura II.3, situada en el centro, presenta una pintura más densa, sobre todo en aquellas zonas no afectadas por la colada. Lo mismo ocurre con el motivo II.4, que podría formar parte de la misma figura. Existen otros motivos que presentan un rojo débil (M10R 5/6, M10R 5/8, M10R 6/8) y un pigmento muy diluido, seguramente como consecuencia de la degradación de la pintura original. El resto de los motivos están realizados con un rojo fuerte (M10R 3/6) y con una pintura ligeramente más densa. No se observa una concentración de estos últimos motivos en ninguna zona del lienzo.

Panel III. En este panel ambos motivos presentan un color rojo (M10R 4/8) y una pintura bastante diluida.

En general, el color más abundante es el rojo (M10R 4/4, M10R 4/6, M10R 4/8), empleándose en los tres paneles y en diversos motivos como antropomorfos de tipo "phi" o de tipo cruciforme, soliformes, barras, ángulos y elementos indeterminados. Otro rojo débil (M10R 5/6, M10R 5/8, M10R 6/8) se ha empleado en algunos motivos del panel II, aunque se trata de figuras muy degradadas, por lo que no pensamos que el color sea indicativo. Un claro ejemplo de ello es el motivo II.18 que presenta un rojo (M10R 4/8) en las zonas mejor conservadas y un rojo débil $(M 10 R 5 / 6)$ en las zonas afectadas por el velo calcítico. En ambos casos la pintura es bastante diluida.

También se ha empleado un color rojo fuerte (M10R 3/6), sólo en algunas figuras del panel II, como una barra (II.13), el antropomorfo en doble "Y" (II.18) y el cruciforme (II.3). En todos los casos observamos que el pigmento es ligeramente más denso.

La técnica empleada en la ejecución del Arte Esquemático de esta zona es la misma, siendo más abundantes las variaciones relativas al color y la densidad de la pintura. En todos los conjuntos de Arte Esquemático de este entorno geográfico (Salt de Penàguila, Port de Penàguila, Barranc de Frainós, Morro Carrascal y Port de Confrides) se ha empleado el rojo, en 
diferentes intensidades que oscilan entre el rojo débil y el rojo fuerte. Sólo en el Panel 1 del Abrigo II del Port de Confrides observamos un conjunto de ramiformes horizontales en los que el color empleado ha sido el negro. Los conjuntos más cercanos a esta zona con pinturas esquemáticas de color negro se encuentran en Alcoy, en el Barranc de les Carrasques; y en Planes, en el Abric del Cantacuc y el Barranc dels Garrofers. (Hernández et alii, 2000).

\section{CONSIDERACIONES CRONOCULTU- RALES DE LOS MOTIVOS DE LA PENYA ROJA.}

Las investigaciones realizadas en las últimas décadas referentes al Arte Esquemático en el País Valenciano (Hernández et alii, 2000; Torregrosa, 1993, 2000-2001; Torregrosa y Galiana, 2001; Pérez Botí, 2001) permiten realizar una aproximación a la cronología de algunos de los motivos de la Penya Roja. Esta aproximación cronológica resulta compleja ya que el Arte Esquemático de esta zona se desarrolla a lo largo de todo el Neolítico.

El motivo antropomorfo en doble $Y$ (motivo II.17), junto a los en $Y$, en $Y$ invertida $y X$, es un tema recurrente en los soportes muebles del Neolítico Antiguo, documentándose en la Cova de l'Or (Martí y Hernández, 1988) y en el Abric de la Falguera (Cardito, 1998). En la Cova de l'Or gran parte de los motivos antropomorfos, soliformes, ramiformes y otros motivos macroesquemáticos proceden de las capas inferiores (Torregrosa y Galiana, 2001: 160). Así mismo se ha hecho referencia a que estos tipos de antropomorfos aparecen pintados en soporte rupestre, tanto en las manifestaciones macroesquemáticas como en las esquemáticas (Martí y Hernández, 1988; Hernández y Martí, 2000-2001; Torregrosa y Galiana, 2001). Recientemente Pérez Botí (2001, 51) apunta la gran similitud existente entre los antropomorfos en $X$ o en $Y$ sobre soporte mueble de la Cova de la Sarsa, con los rupestres localizados en la cabecera del Riu Clariano y el resto de las comarcas alicantinas. Lo mismo podríamos decir para el motivo III.2, ya que presenta los mismos convencionalismos que la figura anterior; e incluso de la figura II.3, con uno de los brazos alzados y bifurcado, tan semejante a algunas representaciones macroesquemáticas.

Respecto a los antropomorfos de tipo "phi" se ha señalado su adscripción cronológica, en estas tierras, a los momentos finales del Neolítico. Martí y Cabanilles (2002, 159-160) relacionan los antropomorfos en "phi" y golondrina de La Sarga con el cierre de la secuencia del Arte Esquemático en este yacimiento. Para ello se argumenta la inexistencia de paralelos de las figuras de tipo "phi" en la cerámica neolítica y la inexistencia en La Sarga de antropomorfos esquemáticos con los brazos levantados. Sólo en un fragmento cerámico con decoración impresa cardial procedente de La Sarsa parecen apreciarse dos figuras humanas con los brazos en asa y, más claramente, las piernas arqueadas y el falo indicado. Torregrosa y Galiana (2001: 159) señalan que podría tratarse de un antropomorfo con los brazos en asa, mientras que Pérez Botí (2001: 51) lo interpreta, simplemente, como un motivo antropomorfo esquemático.

Respecto al motivo II.2 es difícil pronunciarse, ya que tipológicamente podría clasificarse como cruciforme, motivo en $X$ y, con más reservas, de tipo golondrina. Los motivos en $X y$, quizás también, los motivos de tipo golondrina tienen paralelos en la cerámica impresa cardial, como se puede observar en algunas cerámicas de la Cova de l'Or (Martí y Hernández, 1988).

El principal problema a la hora de realizar consideraciones cronoculturales relativas a los antropomorfos es que, si bien es cierto que en nuestras tierras el tema antropomorfo desaparece del registro mueble después del Neolítico Medio (finales del V milenio cal. a.C.) (Hernández et alii, 2000, 64) esto no implica, necesariamente, que no perdure en soporte rupestre durante toda la secuencia neolítica.

Por otro lado, los motivos soliformes están muy bien representados en el registro mueble, documentándose en las cerámicas impresas del Neolítico Antiguo de la Cova de I'Or (Martí y Hernández, 1988, 48), así como en las cerámicas incisas y esgrafiadas de la Cueva del Montgó y en otras cerámicas de la Edad del Bronce (Hernández et alii, 2000, 62). En algunos yacimientos puede señalarse su atribución a momentos del III milenio, como ocurre en el Barranc de Migdia, Barranc de la Palla y en la Penya de l'Ermita del Vicari, al estar asociados a motivos de tipo ídolo, oculados o bitriangulares (Galiana y Torregrosa, 1995; Hernández et alii, 2000, 62).

Lo mismo ocurre con el pectiniforme, tipo que debe perdurar hasta el tercer milenio, como parece indicar su asociación a un antropomorfo de cuerpo bitriangular en la Cova el Barranc del Migdia (Hernández et alii, 2000, 256). 
Los últimos tipos de figuras que encontramos en el yacimiento son los ángulos y las barras. Tampoco es posible determinar su cronología precisa, ya que parecen estar presentes en toda la secuencia.

En definitiva, si bien algunos de los motivos parecen tener su origen en el Neolítico Antiguo, el empleo de los mismos en el arte rupestre pudo darse a lo largo de todo el Neolítico, no pudiendo adscribir el yacimiento a un momento preciso de la secuencia. La ausencia de representaciones claramente atribuibles al III milenio -ídolos- tampoco significa que el yacimiento no pueda corresponder a los momentos finales, ya que su representación no tiene por qué ser homogénea en todos los conjuntos.

No obstante, el estudio de la técnica y la composición parece reflejar que todos los motivos de la Penya Roja se realizaron en un mismo momento.

\section{CONTEXTO ARQUEOLÓGICO DE LA PENYA ROJA. YACIMIENTOS DE HÁBITAT Y CONJUNTOS DE ARTE RUPESTRE NEOLÍ- TICOS EN LA CUENCA DEL RIU PENÀGUILA}

La ubicación de las cuencas de los ríos Seta y Penàguila en las comarcas de l'Alcoià y el Comtat es un factor determinante a la hora de explicar las primeras y tempranas actividades arqueológicas llevadas a cabo en la zona de estudio y su posterior evolución a lo largo de todo el siglo $X X$. La profunda tradición investigadora hace de este territorio uno de los mejor conocidos en cuanto a su poblamiento durante la Prehistoria Reciente.

En las últimas décadas cabe destacar algunos proyectos que se han centrado en la documentación del Arte Rupestre y de los yacimientos de hábitat durante el Neolítico. El primero de ellos se originó cuando, tras el descubrimiento en 1980 del yacimiento de Arte Macroesquemático de Pla de Petracos (Castell de Castells), el Dr. M. S. Hernández y los miembros del Centre d'Estudis Contestans, iniciaron la prospección y catalogación de yacimientos de arte rupestre en las comarcas de La Marina Alta, La Marina Baixa, I'Alcoià y El Comtat. Los resultados se materializaron en 1988 en la publicación del libro Arte Rupestre en Alicante (Hernández et alii, 1988), dándose a conocer cerca de un centenar de yacimientos de arte rupestre.
Por otro lado, entre 1987-1993, el Departamento de Prehistoria y Arqueología de la Universidad de Valencia, en colaboración con la Universidad de Arizona, realizó una labor de prospección en los valles de l'Alcoià y El Comtat, como parte del desarrollo de dos proyectos de investigación: "La transición neolítica: el substrato epipaleolítico y el proceso de neolitización" y "El origen del hábitat estable en superficie". Este último está dirigido por J. Bernabeu y su objetivo principal es el conocimiento de las primeras comunidades agrícolas prehistóricas en la cuenca del río Serpis o d'Alcoi.

En el área de nuestro estudio las prospecciones se centraron sobre todo en la partida llamada Les Puntes y Mas d'Is (Bernabeu et alii, 1989; Bernabeu et alii, 1999), aunque también se llevaron a cabo en el resto del valle, localizando numerosos yacimientos de época diversa (desde el Neolítico Antiguo hasta época Tardorromana). Como consecuencia de estas prospecciones en 1998 se reanudó la excavación en el yacimiento arqueológico del Mas d'Is, excavación que continúa en la actualidad y que forma parte del proyecto denominado "Arqueología y medio ambiente de los primeros agricultores (A.M.A.P.A.)". Parte de los resultados de estas últimas campañas de excavación han sido publicadas recientemente (Bernabeu et alii, 2002; Bernabeu et alii, 2004).

Por último cabe señalar la prospección sistemática llevada a cabo en la zona por uno de los autores de este artículo, J. Molina, centrada en las cuencas de los ríos Seta y Penàguila. Los principales resultados de este trabajo de investigación, dirigido por el Dr. F. J. Jover, han sido la documentación de un poblamiento mucho más denso durante el $\mathrm{Pa}$ leolítico Medio, el Neolítico y el HCT (Molina, 2003; 2005). La amplia información obtenida para el período Neolítico ha permitido evidenciar las diferencias existentes, en cuanto al modelo de ocupación y explotación del territorio, entre el Neolítico Antiguo y las etapas posteriores de este periodo.

\section{V.1. La ocupación del territorio durante el Neolítico}

Los datos ofrecidos por las excavaciones arqueológicas desarrolladas en el Mas d'Is desde mediados de la década de los 90 apuntan hacia una cronología correspondiente a las primeras fases del Neolítico (Bernabeu et alii, 
2002), por lo que, necesariamente, debe proponerse una temprana ocupación de la cuenca del Riu Penàguila dentro del proceso de neolitización al que se ve sometido este territorio.

Aparte del Mas d'ls, se conocen un total de doce asentamientos que según los registros materiales en superficie pueden encuadrarse entre el VI milenio y mediados del $\mathrm{V}$ milenio cal. a.C. Once de estos yacimientos se ubican en la cuenca del Riu Penàguila y uno de ellos aparece localizado en el curso medio del Riu Seta. En este período, lo que se observa es un poblamiento abundante en la zona de la partida de Les Puntes y Els Dubots. La mayoría de los asentamientos se encuentran ubicados entre la sierra de la Serreta y la margen izquierda del Riu Penàguila, contabilizándose hasta un total de 9 asentamientos cuyos conjuntos materiales presentan características que lo sitúan cronológicamente entre mediados del VI milenio hasta mediados del $\mathrm{V}$ milenio cal a.C. Todos los asentamientos aparecen vinculados a cursos de agua, afluentes actuales del cauce principal o Riu Penàguila. A este respecto se ha propuesto recientemente que los primeros yacimientos neolíticos que aparecen en torno al Riu Penàguila se encuentran ocupando zonas húmedas o encharcadas, posiblemente desecadas con anterioridad para su puesta en explotación (Molina, 2005). Este modelo de explotación del medio se basa en que los yacimientos de este período que han sufrido menos transformaciones se encuentran ocupando pequeñas depresiones del terreno, documentándose la existencia de tierras con gran aporte orgánico, moluscos dulceacuícolas y lignitos.

Desde la Penya Roja se tiene perfecto control visual de todos los asentamientos ubicados entre la margen izquierda del Riu Penàguila y las sierras de Els Plans y de Penàguila. El yacimiento de este período más cercano a la Penya Roja es el Barranc de l'Amagat, del cual dista tan sólo 0,5 Km. El más alejado de este foco de poblamiento es el denominado Mas de La Gitana y Les Florències, los cuales distan unos $4 \mathrm{~km}$ de distancia. Otra pequeña concentración de asentamientos parece ocupar las zonas algo más elevadas del valle, en contacto con la zona montañosa, como es el caso de Les Florencies o Mas del Regadiuet.

Desde mediados del $\mathrm{V}$ milenio hasta los inicios del III milenio cal. a.C., se produce un aumento considerable del número de yacimientos y de su tamaño, constatándose, tanto en la cuenca del Riu Penàguila como en el Riu
Seta, una densa ocupación -56 yacimientos (Molina, 2003; 2005)- y una dispersión uniforme en el territorio. Asistimos, por tanto, a una transformación importante en el modelo de poblamiento, dando la sensación de una ocupación total y homogénea de todo el valle y de aquellas laderas que ofreciesen los recursos apropiados. Estos datos hay que manejarlos con precaución debido a que la gran cantidad de yacimientos documentados para estos momentos podría deberse, en parte, a la movilidad de los grupos.

De cualquier forma sí es posible señalar un cambio substancial en las características de los asentamientos de un momento a otro, ya que se pasa de yacimientos de pequeñas dimensiones, no superiores a la media hectárea pero con una gran concentración de materiales arqueológicos, a asentamientos de grandes dimensiones -a excepción del Mas d'ls- donde los restos arqueológicos aparecen dispersos, sin que podamos precisar con exactitud sus límites. Estos cambios los asociamos, entre otras posibles causas, a una transformación en el modelo de explotación agrícola del entorno. Como ya hemos señalado, hasta mediados del $V$ milenio cal a.C. existe una preferencia por ocupar las zonas húmedas, por lo que proponemos que este interés va ligado a la explotación de las tierras más fértiles de origen lagunar. Este tipo de agricultura estaría acorde con pequeños grupos humanos que se enfrentan a la colonización de un territorio desconocido. Con el afianzamiento de estos grupos en el territorio se inicia un cambio en la explotación del medio que permite obtener mayor cantidad de suelo cultivable, aunque de menor calidad. Este nuevo sistema de cultivo, que se constata en la cuenca de los ríos Seta y Penàguila a partir de mediados del $\mathrm{V}$ milenio cal. a.C., pudo fomentar el clareo de amplias zonas mediante el uso del fuego, sistema propuesto por otros autores que señalan su uso desde el inicio del Neolítico (Bernabeu y Martí, 1992, 221-222), si bien originariamente pudo estar orientado hacia la obtención de pastos.

En el III milenio cal. a.C. u Horizonte Campaniforme de Transición, se produce un nuevo y profundo cambio en la ocupación del territorio que se constata en la reducción de los 56 yacimientos de la fase anterior a cinco (Molina, 2003), tres ubicados a lo largo del Riu Penàguila y dos a lo largo del Riu Seta. Los yacimientos se encuentran bastante separados unos de otros ocupando la parte central del valle y jalonando ambas cuencas. El descenso de 
asentamientos con respecto a la etapa precedente parece indicar que se produce la fijación de los grupos a un espacio concreto, lo que ofrece una visión mucho más real de la densidad poblacional (Jover, 1999). A partir de este momento también se documenta un yacimiento funerario en la zona, la Cova de la Pastora, en la que se encontraron ídolos oculados y otros elementos de ajuar característicos del III milenio.

\section{V.2. Conjuntos de Arte Rupestre en la cuen- ca de Riu Penàguila}

Los abrigos con arte rupestre localizados en la cuenca del Riu Penàguila son escasos y se ubican, fundamentalmente, en la propia cabecera del río o en su curso alto (Fig. 7). El yacimiento de la Penya Roja constituye, en este sentido, una clara excepción.

En primer lugar debemos hacer referencia a las pinturas localizadas en el Barranc de Frainós y en el Morro Carrascal (Hernández et alii, 1988; 1998; 2000), ubicados en la sierra de Aitana y pertenecientes al término municipal de Alcoleja. Todos los abrigos se encuentran situados a una cota cercana a los $1000 \mathrm{~m}$ s.n.m, se encuentran próximos a la vía de paso que conecta con la zona de Sella y la costa y, al mismo tiempo, tienen un buen control visual sobre el paisaje montañoso cercano.

En el Abrigo I del yacimiento de Barranc de Frainós se documentan motivos esquemáticos, destacando la presencia de barras verticales de pequeño tamaño y un ramiforme de desarrollo vertical (Hernández et alii, 2000). En el Abrigo II se han identificado otros motivos levantinos (Hernández et alii, 1998).

En el cercano Abrigo I del yacimiento de Morro Carrascal se documenta otro pequeño conjunto de Arte Esquemático, destacando pequeñas barras de tendencia vertical y un motivo en $Y$ con el extremo inferior de la barra vertical prolongada hacia la izquierda, pudiéndose tratar de una figura humana sentada (Hernández et alii, 2000).

El segundo conjunto de arte rupestre se ubica en el paraje conocido como el Salt de Penàguila y Port de Penàguila, donde se han localizado conjuntos de Arte Levantino y Esquemático (Beltrán, 1974; Hernández et alii 1981; 1998 y 2000). Las pinturas del Salt de Penàguila se localizan en el interior de un barranco abrupto en las cercanías de dicha población. Sin embargo, el denominado Abric de
Santa Llúcia se encuentra situado en la parte más elevada de la falla, desde donde se tiene un formidable control visual del valle, debido a su proximidad. Desde el resto de abrigos la visibilidad es prácticamente nula al quedar orientados hacia el interior del barranco.

Los motivos esquemáticos del Barranc del Salt forman el conjunto más rico detectado hasta la fecha en la cuenca del Riu Penàguila. Cabe destacar en el Abrigo I la presencia de un circuliforme. En el Abrigo II se observan restos de pequeños circuliformes, barras de tendencia vertical y restos de una posible figura humana. En el Abrigo III se documentan algunas figuras humanas, una de unos $14 \mathrm{~cm}$ de largo y otra en la que se conserva el cuerpo, el falo y las extremidades inferiores. En el Abrigo IV, o Arco de Santa Llúcia, cabe mencionar la presencia de conjuntos de hasta 11 barras verticales, zigs-zags horizontales y un posible circuliforme. Por último, en el Abrigo VI cabe destacar la presencia de una figura humana $O$ ídolo ancoriforme, motivos en $\mathrm{Y}$, en doble $\mathrm{Y}$, figuras humanas con los brazos en cruz y piernas en $V$ invertida, otras con barras perpendiculares cortando el tronco y el falo prolongado, pectiniformes, etc. Cabe mencionar que es en este conjunto donde se documentan los paralelos más cercanos a la Penya Roja.

Los abrigos del Port de Penàguila se encuentran orientados hacia el valle, localizándose en una de las vías naturales de comunicación del valle de Penàguila hacia la costa. En el Abrigo I se documentan diversos motivos levantinos mientras que los motivos esquemáticos aparecen representados en el Abrigo II, destacando la presencia de barras verticales, pectiniformes, un tectiforme, dos cápridos, restos de un serpentiforme vertical, un soliforme y un escaleriforme (Hernández et alii, 1998).

Por último, hay que hacer referencia a las pinturas levantinas del Port de Confrides (Hernández et alii, 1988; 1998), ubicadas en un espolón rocoso de la sierra de la Serrella, en el término municipal de Confrides. Al igual que los conjuntos de arte rupestre descritos anteriormente, las pinturas del Port de Confrides se encuentran ubicadas en una vía de comunicación natural hacia la zona de la Marina Baixa, siguiendo el curso del Riu Penàguila. La visibilidad desde el abrigo es amplia, ya que se encuentra a $830 \mathrm{~m}$ s.n.m, con un paisaje eminentemente abrupto y montañoso que queda alejado de las zonas de valle. Dentro de este conjunto encontramos, en los Abrigos I y III, una 

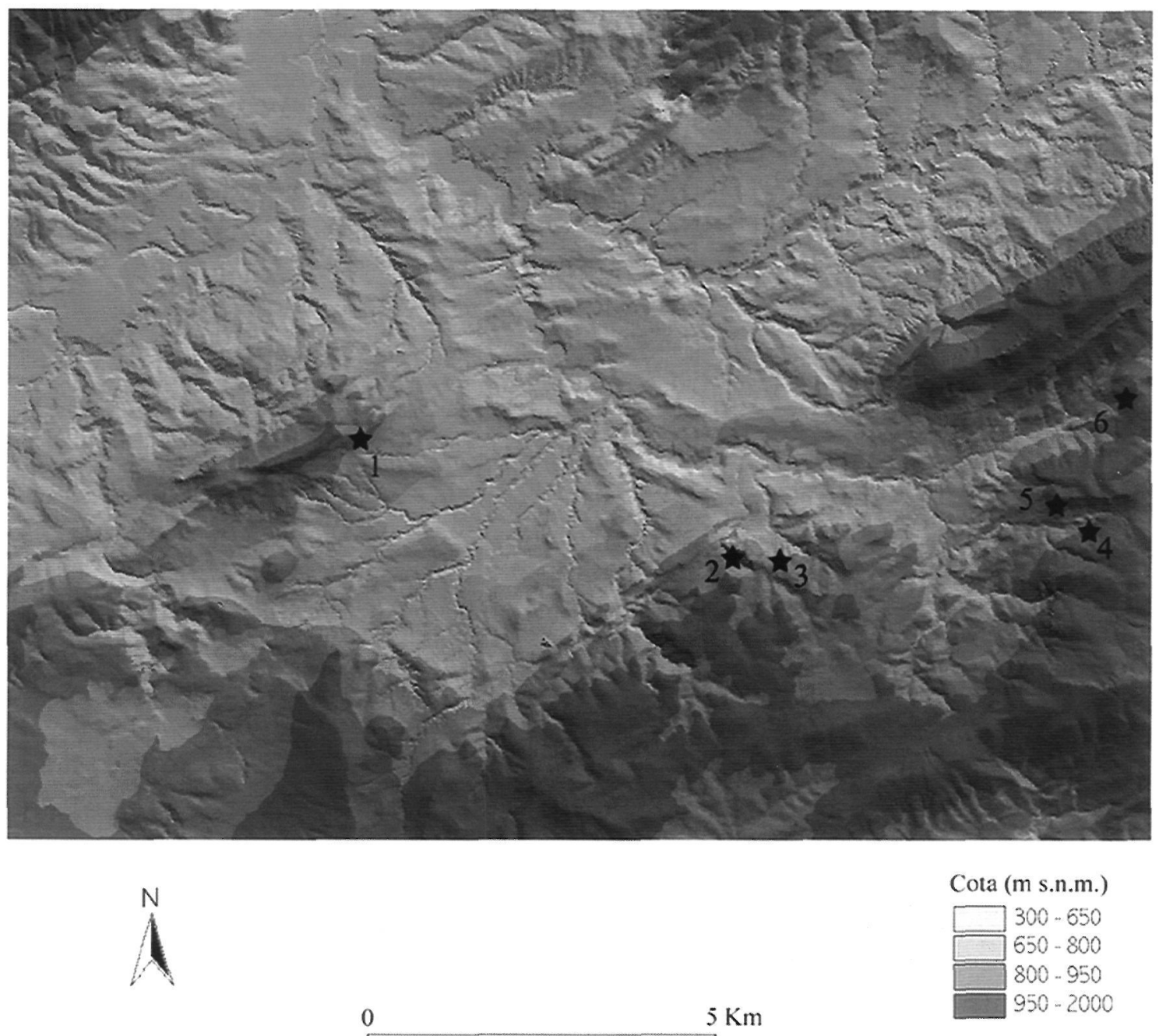

Figura 7: Ubicación de los yacimientos de Arte rupestre en la cuenca del riu Penàguila. 1.- Penya Roja (Cocentaina). 2.Barranc del Salt (Penàguila). 3.- Port de Penàguila (Penàguila). 4.- Barranc de Frainós (Alcoleja). 5.- Morro de les Carrasques (Alcoleja). 6.- Port de Confrides (Confrides).

barra vertical y varios ramiformes horizontales que pueden adscribirse al Arte Esquemático. No obstante, destaca el Abrigo II, con un importante conjunto de pinturas levantinas.

\section{V.3 Distribución espacial de los abrigos con Arte Rupestre en la Cuenca del Riu Pe- nàguila}

La Cuenca del Riu Penàguila es, actualmente, una de las áreas mejor conocidas, tanto en lo referente al arte rupestre como a los yacimientos de hábitat. Esto permite llevar a cabo un interesante estudio acerca de la distribución de los abrigos y de su relación con el hábitat prehistórico, aspecto que resulta clave para la interpretación.
En algunos trabajos referentes al análisis en el paisaje de los abrigos con Arte Esquemático (Martínez, 1998; 2000; Torregrosa, 2000-2001) se han establecido distintas categorías en función del emplazamiento de los conjuntos. En este caso, la Penya Roja se encuentra en un cerro en el centro de las comarcas de I'Alcoia y el Comtat, siendo el único abrigo con arte rupestre ubicado en un cerro aislado de amplio dominio visual con respecto al valle, lo que permite clasificarlo como un abrigo de visión (Martínez García, 1998) o dentro de lo que Torregrosa (2000-2001) denomina Patrón de emplazamiento asociado a un cerro o montaña individualizado en el paisaje. Los estudios que se han realizado en esta zona (Torregrosa, 2000-2001; Fairén, 2002) atestiguan que se trata del único abrigo de visión 
dentro de la cuenca del Riu Serpis y que sólo existen tres más con similares características en su emplazamiento dentro de lo que Torregrosa denomina grupo 1 , que comprende la cuenca del Serpis, las cuencas menores de la Marina, la cuenca del río Albaida y la cuenca del río Canyoles (Torregrosa, 2000-2001). Se trata de los yacimientos de Abric de Seguili, Coves Santes de Dalt y Coves Santes de Baix, todos ellos en la cuenca del Riu Xaló y todos ellos conjuntos exclusivamente esquemáticos.

No obstante, en el análisis de la distribución de los abrigos en el paisaje es importante considerar no sólo la posición del abrigo en un determinado accidente geográfico, sino también la posición del accidente geográfico en el territorio (Martínez, 1998: 550). Es decir, independientemente de la unidad geográfica inmediata y de la visibilidad del abrigo y desde el abrigo, resulta fundamental conocer si el accidente geográfico en cuestión está vinculado a un valle, a un corredor o a un barranco. Un claro ejemplo es el Salt de Penàguila, en el que encontramos una serie de abrigos dentro de un barranco que, a su vez, está abierto y próximo al valle.

Partiendo de esta consideración podemos decir que, al menos en esta zona, los conjuntos esquemáticos más importantes siempre se dan en los yacimientos vinculados al llano, como son el Salt de Penàguila y la propia Penya Roja, en los que encontramos conjuntos exclusivamente de Arte Esquemático. Por otro lado, en los yacimientos localizados en vías de paso o zonas de montaña más alejadas del valle predominan los motivos levantinos. Un claro ejemplo de ello sería el Port de Confrides, en el que frente a, al menos, 13 figuras levantinas tan sólo encontramos una barra y un conjunto de ramiformes de tipo esquemático. El yacimiento del Port de Penàguila reúne ambas características físicas; localizado en una zona de paso se encuentra también próximo al valle, dominando buena parte de él. Curiosamente, en este yacimiento se localizan dos conjuntos importantes de arte, uno Esquemático y otro Levantino. Cada uno de ellos se dispone en abrigos diferentes y se podría decir que, en este caso, ninguna de las manifestaciones es marginal.

\section{CONCLUSIONES: ARTE Y TERRITORIO EN LA CUENCA DEL RIU PENÀGUILA}

La importancia del yacimiento de la Penya Roja radica en varios aspectos. Por un lado en el propio hallazgo de un nuevo conjunto de Arte Esquemático. Por otro lado, en la posibilidad de relacionar este yacimiento con uno de los focos neolíticos más importantes y mejor documentados de estas tierras.

Teniendo en cuenta todos los aspectos analizados en este estudio, las conclusiones a las que llegamos son las siguientes:

- La técnica y el color empleados en la elaboración de las pinturas de la Penya Roja es homogénea en toda la zona estudiada. Se trata de figuras realizadas, mayoritariamente, en tinta plana, con un contorno irregular y un color rojo cuya intensidad oscila entre el rojo débil y el rojo fuerte. Sólo en el Port de Confrides se ha empleado también el color negro. El pigmento es, generalmente, diluido y sólo algo más denso en los motivos realizados en rojo o rojo fuerte.

- Tipológicamente, en la Penya Roja encontramos motivos antropomorfos - uno en doble $Y, 6$ de tipo "phi" y un cruciforme-, un soliforme, un pectiniforme, un ángulo y varias barras. Los motivos de este conjunto encuentran paralelos en yacimientos próximos. Salvo la figura II.3, que muestra ciertas características poco frecuentes en el Arte Esquemático y la figura II.6, que presenta un tipo de adorno o peinado para el que no hemos encontrado paralelos en el área. Los antropomorfos de tipo "phi" tampoco tienen paralelos claros en los conjuntos más próximos. En el norte de la provincia de Alicante existen algunos ejemplos de este tipo de antropomorfos, como por ejemplo en el yacimiento de La Sarga (Alcoy). No obstante son escasos, siendo un tipo de figura mucho más abundante en el sur peninsular.

- La composición del conjunto de forma homogénea y sin superposiciones podría indicar que éste se efectuó en un solo momento. Además, es posible distinguir algunas asociaciones entre determinados motivos - algunas, incluso, recurrentes en otros conjuntos -, identificando composiciones difíciles de interpretar. El soporte se ha empleado para separar esas composiciones formadas por varios motivos y para destacar algunas figuras.

En cuanto a la cronología del yacimiento las conclusiones que podemos extraer no son determinantes, aunque el estudio de la composición parece señalar un solo momento de ejecución. Se han representado motivos con paralelos claros en las cerámicas del Neolítico Antiguo y Medio, pero esto no 
supone, necesariamente, que no perduren en el soporte rupestre hasta el final de la secuencia. Por otro lado, encontramos un tipo de antropomorfo -"phi"- que se adscribe a los momentos finales del Neolítico en estas tierras, siendo muy vago el único indicio que tenemos acerca de su representación en cerámica cardial.

- Desde el punto de vista de la ubicación del yacimiento, la Penya Roja es un abrigo de visión localizado en una montaña aislada desde la que se tiene un perfecto dominio visual del valle. Tan sólo otros tres yacimientos en todo el Grupo 1, localizados en la cuenca del Riu Xaló, pueden adscribirse dentro de esta categoría y los cuatro son yacimientos exclusivamente esquemáticos. En el caso de la Penya Roja esta característica podría vincularse al intenso poblamiento que se da en el valle desde los primeros momentos de la neolitización y durante todo su desarrollo. Los yacimientos localizados en la desembocadura del Riu Xaló también han sido vinculados a la existencia de yacimientos de hábitat como la Cova del Montgó (Torregrosa, 2000-20001: 46).

- En este sentido, debemos insistir en que en esta zona los conjuntos esquemáticos más importantes siempre se dan en los yacimientos vinculados al llano, como son el Salt de Penàguila y la propia Penya Roja, en los que encontramos conjuntos exclusivamente de Arte Esquemático. Mientras que en los yacimientos localizados en vías de paso o zonas de montaña más alejadas del valle predominan los motivos levantinos, en algunos yacimientos como el Port de $\mathrm{Pe}$ nàguila la aparición de los dos tipos de arte de forma equitativa podría deberse a su condición de vía de paso y, al mismo tiempo, su proximidad al valle.

- En base a lo anteriormente dicho, es posible que conjuntos como la Penya Roja y EI Salt y Port de Penáguila reflejen la consolidación de unos grupos neolíticos en un territorio. Todo ello mediante la elección, para realizar las representaciones, de lugares próximos al valle que delimitan, con una tendencia circular o envolvente, los espacios habitados.

\section{Agradecimientos}

Nos gustaría agradecer la ayuda prestada en la realización de este trabajo a Mauro Hernández, Ma Francia Galiana, Pere Ferrer,
Palmira Torregrosa, J. María Segura, Fco. Javier Jover, Ignacio Grau y Germán Pérez.

Virginia Barciela González

Area de Prehistoria

Dpto. de Prehistoria, Ar-

Fco. Javier Molina Hernández c/ Luis Braille, 17, $4^{\mathrm{a}}$ dcha.

queología, $\mathrm{H}^{\mathrm{a}}$ Antigua,

Filología Griega y Filología

Latina

Facultad de Filosofía y Letras

Universidad de Alicante

Apdo. 99

03080 Alicante

virginia.barciela@ua.es

\section{BIBLIOGRAFÍA}

BELTRAN, A., 1974: "Las pinturas rupestres de la Sarga (Alcoy), EI Salt (Penáguila) y El Calvari (Bocairente)", TV del S.I.P., 47, Diputación Provincial de Valencia.

BERNABEU, J. y MARTí, B., 1992: “EI País Valenciano de la aparición del Neolítico al horizonte campaniforme", Aragón/Litoral mediterráneo. Intercambios culturales durante la Prehistoria, 213-234. Zaragoza.

BERNABEU, J., GUITART, I. y PASCUAL, J. LI., 1989: "Reflexiones en torno al patrón de asentamiento en el País Valenciano entre el Neolitico y la Edad del Bronce", Saguntum-PLAV, 22, 99-123.

BERNABEU, J., BARTON, C. M., GARCÍA, O. y LA ROCA, N., 1999: "Prospecciones sistemáticas en el Valle de Alcoi (Alicante). Primeros resultados", Arqueología Espacial, 21, 29-64.

BERNABEU, J., OROZCO, T. y DÍEZ, A., 2002: “EI poblamiento neolítico: desarrollo del paisaje agrario en les Valls de I'Alcoi", Hernández, M.S. y Segura, J.M. (coords.): La Sarga. Arte rupestre y territorio, 171-184. Alcoi.

BERNABEU, J., OROZCO, T., DIEZZ, A., GÓMEZ, M. y MOLINA, F.J., 2004: "Mas d'Is (Penàguila, Alicante): aldeas y recintos monumentales del Neolítico Inicial en el valie del Serpis", Trabajos de Prehistoria, 60: 2, 39-60.

CARDITO, L. Ma , 1998: "Arte macroesquemático y paralelos mediterráneos: apuntes para su cronología", SaguntumPLAV, 31, 99-107.

FAIRÉN JIMENEZ, S., 2002: El paisaje de las primeras comunidades productoras en la cuenca del rio Sérpis (País Valenciano), Villena.

GALIANA, M. F. y TORREGROSA, P. 1995: "Las pinturas rupestres de la Penya de l'Ermita del Vicari (Altea, Alicante)", Zephyrus, XLVIII, 299-315.

HERNÁNDEZ, M. S., FERRER, P. y CATALÁ, E., 1988: Arte rupestre en Alicante, Alicante.

HERNÁNDEZ, M.S., FERRER, P. y CATALÁ, E., 1998: L'art Llevantí. Catàleg de l'exposició, Cocentaina.

HERNÁNDEZ, M.S., FERRER, P. y CATALÁ, E., 2000: L'Art Esquemàtic. Catàleg de l'exposiciò, Cocentaina.

HERNÁNDEZ, M.S. y MARTÍ, B., 2000-2001: "EI Arte Rupestre de la fachada mediterránea: entre la tradición epipaleolítica y la expansión neolítica", Zephyrus, 53-54, 241-265.

I.G.M.E., 1979: Mapa geológico Nacional de España. Escala 1/50.000. Hoja 821 (AlCoi) y 847 (Villajoyosa), Madrid.

JOVER, F. J., 1999: Una nueva lectura del "Bronce Valenciano", Alicante

LA ROCA, N., 1991: "Untersuchungen zue räumlichen und 
zeitlichen Variabilität der Massenbewegungen im Einzugsgebiet des Riu d'Alcoi (Alicante, Ostpanien), Die Erde, 122, s: 221-236.

MARTÍ, B. y HERNÁNDEZ, M., 1988. El Neolitic Valencià. Art rupestre i cultura material. Servicio de Investigación Prehistórica. Valencia.

MARTÍ, B. y JUAN-CABANILLES, J., 2002: La decoració de les cerámiques neolítiques i la seua relació amb les pintures rupestres dels abrics de la Sarga. La Sarga. Arte rupestre y territorio, 147-170. Alcoi.

MARTINEZ GARCÍA, J., 1998: "Abrigos y accidentes geográficos como categorias de análisis en el paisaje de la pintura rupestre esquemática. El sudeste como marco", Arqueologia Espacial, 19-20, Teruel.

MARTINEZ GARCIAA, J., 2002: "Pintura rupestre esquemática: el panel, espacio social", Trabajos de Prehistoria, 59: 1, 65-88.

MOLINA, F. J., 2003: El poblamiento en las cuencas de los ríos Seta y Penàguila. Trabajo de Investigación inédito.

MOLINA, F. J., 2005:" Poblamiento durante el Neolítico I en la parte occidental de las comarcas de l'Alcoià y El Comtat (Alicante), a partir de la localización de nuevos yacimientos al aire libre", XXVII Congreso Nacional de Arqueología, I. Prehistoria (Huesca, 2003), Bolskan, 18, 195-206.

MOLINA, F.J. y SEGURA, J.M., 2001: "Arte rupestre esquemático en Alcoi. Nuevas aportaciones", Recerques del Museo d'Alcoi, 10, 59-72.

PASCUAL, J. LI., 1986: "Les Jovades (Cocentàina). Notes per a l'estudi del poblament eneolític a la conca del Riu d'Alcoi", El Eneolitico en el Pais Valenciano: 73-87. Alicante.
PEREZ BOTÍ, G., 2001: "La Cova de la Sarsa (Bocairent, Valencia). La decoración figurada de su cerámica neolítica. Una aproximación cronocultural", Recerques del Museu d'Alcoi, 10, 43-58.

ROSELLÓ, V. M. y BERNABÉ, J. M., 1978: "La montaña y sus valles: un dominio subhúmedo", Geografia de la provincia de Alicante, 77-119.

SIMÓN, J. L., 1995: "Contribución a la metalurgia del bronce final en las comarcas centrales valencianas. Las hachas de apéndices laterales", Recerques del Museu d Alcoi, 4: 177-183.

SORIA LERMA, M. y LÓPEZ PAYER, M.G., 1988-1989: "Aproximación al estudio del significado de la Pintura Rupestre postpaleolítica del Sureste Peninsular", Ars Praehistorica, VII-VIII, 167-182.

TORREGROSA GIMENEZ, P., 1993: "Distribució de la pintura rupestre esquemática al País Valencià, Butlletí de I'Associació Arqueològica de Castelló, 13, 11-17.

TORREGROSA GIMÉNEZ, P., 2000-2001: "Pintura rupestre esquemática y territorio: análisis de su distribución espacial en el levante peninsular", Lucentum, XIX-XX: 39-63.

TORREGROSA GIMÉNEZ, P. y GALIANA BOTELLA, M.F., 2001: "El Arte Esquemático del Levante peninsular: una aproximación a su dimensión temporal", Millars, espai $i$ història, vol. XXIV, 153-198.

TORREGROSA, P., GALIANA, M.F. y RIBERA, A., 2001: "Els abrics del Barranc de la Mata (Otos, Valencia) i la caracterització de la pintura esquemàtica a la Serra del Benicadell", Quaderns de Prehistoria i Arqueologia de Castelló, n 22. 